\title{
Psychological Peculiarities of Decision Making by Health Professionals in Various Conditions
}

\author{
Tatiana Ryabova \\ Candidate of Psychological Sciences, Associate Professor of the Department of Medical and General Psychology and \\ Pedagogy of Kazan State Medical University; tatry@rambler.ru
}

\section{Doi:10.5901/mjss.2015.v6n6s5p217}

\section{Abstract}

This article contains the data and the research analysis for the psychological features of the decision making process performed by health professionals in various conditions of professional activity: the emergency worker and the outpatient reception doctors. The data resulting from the study suggest qualitative difference in the decision-making process between the emergency doctors and the outpatient physicians as far as informational, procedural /cognitive, communicational, vigilance and procrastination factors are concerned. Emergency physicians have shortage of information, limited quantity of information confining the rationality of decision resulting in increase of clinical intuition role relying on the doctor's experience. To improve effectiveness of the medical service activities, the obtained data of the carried out study can be used by the emergency medical services coordinators for professional selection of emergency doctors, be a source of information as basic data for further studies in this field; and applied by the psychologist working in emergency call services.

Keywords: decision making, emergency worker, vigilance, procrastination, informational factor, decision making questionnaire.

\section{Introduction}

Reform measures of the Health Care System in Russia imply reforms in Emergency Medical Services (EMS), particular attention being paid to improving the efficiency of its resources utilization including human resources. Improvement of EMS organization and delivery requires improvement of medical aid quality, EMS intensification and performance improvement.

The work of the EMS members performed in emergency and extreme situations requires clear-cut and immediate decision making. Extreme situations, which the EMS workers deal with, are highly ambiguous and emotionally stressful, therefore it is important for them to have well-developed quick decision making skills, ability to predict, anticipate the consequences of the decision made for rendering full range of aid to ill and injured persons.

\section{Literature Review}

Decision making is a substantial part of any professional activity. The works of many authors are devoted to the problem of effective decision making in clinical practice of doctors of different specialties. Thus, J. Grupman analyses peculiarities of the physicians' thinking on diagnostic and therapeutic decision making (Grupman, 2008).

Decision making means an act or process of choosing a preferred option or course of action from a set of alternative. It precedes and underpins almost all deliberate or voluntary behavior. Three major classes of theories have guided research into decision making: normative, descriptive (or positive) and prescriptive theories (Kaneman, 2014). Decision making is associated with such notions as a dual - process model, normative, the Allais - paradox, behavioral decision theory, bounded rationality, certainty effect, common ratio effect, cost - benefit analysis, decision theory, dominant alternative/strategy, elimination by aspects, the Ellsberg paradox, framing effect, game theory, heuristic, lexicographic choice, multi - attribute decision making, , prospect theory, psychological decision theory, rational choice theory, readiness potential, risk aversion, risk seeking, social dilemma, subjective expected utility theory, sure - thing principle, utility theory (Colman, 2009).

M. Standing studied clinical judgements and decision making in nursing students and identified the following types of decision making in nurses: collaborative clinical decision - making (consultation, negotiation and cooperation skills with patient and other health professionals in delivering care); using observation to inform decision (emphasizes the importance of what nurses see or hear as evidence about patients' physical or mental health to inform decision); 
systematic clinical decision - making (combines critical thinking and problem solving skills to comprehensively asses, plan, deliver care, review and revise outcomes); standardized clinical decision - making; prioritizing decision in delivering care ( undertaking risk assessment and management informs the way in which resources are targeted nationally and locally in healthcare; experience and intuition in decision - making (accumulate a subconscious repertoire of knowledge and skills that we draw upon when events prompt us to do so); reflective judgement and decision - making ( to consciously review personal, theoretical and practical understanding of clinical situation as a guide to future action); confidence in clinical decision - making (develop self - assurance and professional assurance to inspire confidence in patients and team members that you can be trusted) (Standing, 2011).

Only some national/Russian researchers paid attention to the problem of decision making (Karpov, 2003). Although decision-making can be qualified as "a center", around which the activities of professionals of various types and levels revolve (Leontev, 2014). In such a case the field of decision-making by physicians in different conditions of professional activity remains practically unstudied.

The aim of our research was to study psychological peculiarities of decision making process performed by emergency physicians and physicians working not under extreme conditions, but outpatient physicians or the ones running on schedule.

\section{Study Methods and Study Scheme}

The investigation was carried out in the 2010 - 2015s on the basis of the State Autonomous Healthcare Institution "Emergency Medical Station" of the city of Kazan and on the basis of the Republican Clinical hospital.

Phases of Investigation:

The first phase (2010 - 2013) - exploratory-and-analytical: choice of the research problem, insight into literature and periodicals, goal and task setting, selection of research subjects and techniques.

The second phase (2013 - 2014) - experimental: conduct of the study, the material processing and systematization, analysis of the obtained results.

The third phase (2014 -2015) - making sense of the obtained results, presentation of the obtained data in the form of a research paper.

71 persons aged from 23 to 45 ( $M=31.0 ; S D=5.71 ; 42$ males and 39 females) with accumulated period of work in emergency medical service from 2 to 26 years $(M=10.0 ; S D=6.8)$ took part in the study.

Persons also making decisions in the field of medicine, yet not working under extreme conditions were selected as control subjects. The controls (54 persons) were physicians of different specialties: outpatient physicians or the ones running on schedule (therapeutists, dentists, psychiatrists, gynecologists) with accumulated period of work not less than 3years.Gender differences were not taken into account within the frames of this study.

Methods: The Melbourne Decision Making Questionnaire (MDMQ): a Russian adaptation (Kornilova, 2013). The Questionnaire consists of 22 statements estimated according to 3-point scale. It helps to diagnose such four traits as Vigilance, Avoidance (Buck-passing), Procrastination and Hypervigilance. They can be treated as productive (Vigilance) and non-productive copings on decision making.

Eysenck Personality Questionnaire, 2 factors out of the "Big Five". It allows diagnosing such factor as extraversion, which relates to assertiveness, enjoyment of human interactions or social settings and risk-taking. One of the Big Five personality factors, ranging from one extreme extraversion, characterized by traits such as sociability and assertiveness, to extreme introversion, characterized by reserve and passivity. Other factor - neuroticism, which relays levels of anxiety, ability to deal with stress and maintaining calmness under pressure. One of the Big Five personality factors, ranging from one extreme of neuroticism, including such traits as nervousness, tenseness, moodiness, and temperamentality, to the opposite extreme of emotional stability.

Questionnaire "Estimation Scale of System Decision Making Peculiarities" (ESSDMP) (Ryabova \& Shevtcov, 2010). The Questionnaire consists of 50 statements estimated according to 4-point scale. It allows diagnosing 5 factors associated with effective decision making in the professional activity such as: informational, procedural /cognitive, emotional - volitional, motivation and communicational.

V.D. Mendelevich Prognostic Competence Questionnaire (Mendelevich, 2011). It helps to determine personal prognostic competence. This factor shows ability to predict interpersonal relationships, understand their mood forestalling (predetermining) their further behavior.

Psychodiagnostic techniques to be completed were presented to control and experimental groups (10-25 persons). Similarities and differences in gender, accumulated period of work and kind of activity were estimated. Analysis of decision making peculiarities and established correlation associations between indices was carried out thereafter. A 
hypothesis on decision making styles differentiating groups of persons with different accumulated period of work was tested with statistical techniques (SPSS 22.0, EQS 6.1 for Windows).

\section{Results and Discussion}

The following results were obtained after processing of the Melbourne Decision Making Questionnaire (MDMQ) results. The average values of vigilance or awareness were $15.3 \pm 3.0$ scores. Readiness for making decisions was found to be very high (76.9\%) in emergency physicians at any time and to have average values in $65.4 \%$ of inpatient physicians. Low vigilance indices were estimated in $7.7 \%$ of emergency physicians and in $25.3 \%$ of the control subjects (significant differences, $t=-2.74$ at $p<0.05$ ).

The emergency physicians don't avoid self-decision making (average values of the "Avoidance" Scale $8.7 \pm 2.2$ scores), and inpatient physicians prefer to consult their colleagues in $58 \%$ of cases (significant differences, $t=-2.35$ at $p<0.05)$.

Postponement of making decisions is not typical for the emergency physicians: the scores according to "procrastination" scale are below normal in $83.7 \%$ of the subjects. The inpatient physicians have subnormal scores in $32.5 \%$ of the subjects.

Also, according to the "Hypervigilance" Scale - the average values of unjustified ambivalence between different alternatives are within normal limits in $23 \%$ of emergency doctors.

Thus, on decision making, the emergency physicians as compared with control subjects demonstrate their readiness for decisions at any time, skills for timely signal detections and carrying out required actions without putting the work off for a later time; and doubt in choice between alternatives is not characteristic of them.

Extraversion indices have no significant differences in medical workers of the experimental and control groups. Note that extraversion is high in $61 \%$ of the subjects from emergency physicians, and high values are found in $31 \%$ of the surveyed from the control group. It means that majority of the EMS workers are described as the ones having assertiveness, enjoyment of human interactions or social settings and risk-taking.

The Neuroticism Scale determines the level of the individual emotional stability: from anxiety, sensibility and rapid changes of mood to calmness and emotional balance. Neuroticism indices have average values in $53 \%$ of the EMS subjects, and high values are found in $39 \%$. High values of neuroticism are typical for $26 \%$ of the inpatient physicians and the average ones are typical for $45 \%$. It means that low levels of anxiety, ability to deal with stress and maintaining calmness under pressure are not characteristic of physician assistants. Consequently, the workers of the control group are calmer, less anxious and less susceptible to stress.

The results of the study according to ESSDMP questionnaire showed that emergency medical workers had higher values than inpatient physicians with respect to informational (in 59\% of the surveyed) procedural/cognitive (in 52\%) and communicational (in $71 \%$ ) factors.

After study the following differences in the answers to the information block questions were revealed in the groups of EMS medical workers and physicians working not under extreme conditions. The EMS medical workers are distinguished by more developed ability to take into account the past experience and rely on intuition in comparison with the second group.

The EMS medical worker doesn't "reject" an unusual element, an atypical fact or manifestation, which doesn't fit into decision, pays attention to it; takes into consideration on information processing. They consider that their storage of knowledge and experience is sufficient for successful work $(t=-2.39$ at $p<0.05$, where $t-$ Student $t$-test, $p-$ confident factor values).

Skills to assess the credibility of an information source are more developed in outpatient physicians. At first they study the whole information, facts, and then they speculate and make decisions, frequently relying on certain, previously formed action sequences (decision algorithm).

Thus, the work with information in EMS medical workers differs considerably from that of the outpatient physicians. Sometimes emergency physicians have shortage of information, limited quantity of information confining the rationality of decision resulting in increase of clinical intuition role relying on the doctor's experience. Moreover, high rate of obtaining, inconsistency of information, redundancy and arrhythmy in presentation of information, subjective ambiguity of the information presentation time provide skills for paying attention to atypical manifestations, acting without applying a template, but developing a creative approach to problem solving. The group of outpatient physicians differs from the emergency physicians in that they are more inclined to carry out a thorough logical analysis, weigh all pros and contras, think over all consequences, all possible options, even if they are improbable.

EMS doctors and other medical workers prefer the shortage of time $(t=-2.74$ at $p<0.05)$ on decision making. 
When working in limited time conditions the internal human resources are mobilized, which brings a number of mechanisms, which are to provide overcoming of the emerging difficulties, into action, thereby a rearrangement of the work methods takes place. However in such a case an overstrain of the nervous system can lead to "collapses", aggravation of the state of health of the EMS medical worker himself. Furthermore, the workers' continuous tension manifested by their permanent readiness for emergency visits, imbalance of the sleep-wake rhythm, when they are on duty, result in asthenization of the nervous system and development of somatic diseases in EMS physicians and physician assistants.

When answering the questions of the emotional - volitional quality block the EMS personnel differs by higher values in those indices of the decision making questionnaire, according to which they consider themselves to be responsible for decisions made; combine successfully risk with due diligence in action; behave as assertive people; they are always mobilized and ready for action.

Significant differences in indices are revealed between the outpatient physicians and emergency physicians, according to which the latter control their emotional state more strongly on decision making. M. F. Luce study the influence of emotions on decision making and its result (Luce et. al., 2005). They show that people spend more time on making important, highly charged decisions and study a large quantity of information. It is accompanied with their wish to hold or minimize negative/adverse emotions. They try to apply more efforts into decision processing, try to work well on important decision making, but not necessary better. Such problem-oriented behavior in the decision making process is consistent with the goal of maximizing accuracy of the decision, creation of better decisions and reflects the individual's ability to concentrate under extreme conditions. Thus, the EMS medical workers control their emotional state better than the inpatient workers on decision making.

The findings according to the V.D. Mendelevich questionnaire of prognostic competence showed that personality prognostic competence is high in majority of the EMS medical workers (77\%) and in the inpatient medical workers (55\%). It means that they have a well-developed ability to predict interpersonal relationships.

Correlation analysis showed that the older the EMS medical workers are, the less avoidance of self-decision making, unjustified ambivalence between various alternatives of decision making are common to them $(-0.451$ at $p<$ 0.05 , the correlation between age and hypervigilance indices). The older the subjects of the experimental group are, the more they prefer to associate with people, appreciate the teamwork abilities, get satisfaction from interacting with others ( 0.416 at $p<0.05$, the correlation between age and communicational factor according to ESSDMP on decision making.

The longer the accumulated period of work in EMS is, the more physician assistants rely on the cognitive parameters (the correlation between indices of the accumulated period of work and a cognitive factor according to ESSDMP -0.540 at $p<0.005$ ) on decision making. That is, the ability to form quickly $4-5$ decision options improves with extension of the working period, they think over all possible consequences of decisions made, try to predict, to foresee future events. They think and act very attentively and prefer shortage of time.

Significant correlations between age and working period indices were not revealed in the control subjects.

We established positive correlation association between the vigilance index according to the MDMQ and a cognitive factor according to ESSDMP in EMS workers (0.612 at $p<0.05)$. Consequently, the more the subjects demonstrate readiness for action and mobilization, the more they think by a combination of various factors, information, manifestations, rather than sequentially or step by step. They can easily visualize the situation created. They group different situational elements between themselves and combine various options.

We found negative association of procrastination with the communicational factor index according to the ESSDMP questionnaire and the extraversion index in EMS medical workers $(-0.437$ at $p<0.05)$. It means that the more people are inclined to delay in decision making, the more they are sociable, impulsive, active and inclined to adhere to an opinion of experienced people, colleagues, tutors, "figures of authority" in the given field. It disagrees with the data obtained by Steel, which showed that procrastination was negatively associated with the extraversion factor out of "Big Five" (Steel, 2007).

Negative association of procrastination with the emotional - volitional factor indices in EMS medical workers (- 0 . 528 at $p<0.05)$ is established as well. It means that the more they work towards achieving goals, the less inclined to putting off the decision. The emergency medical workers consider that when there is a choice between options, it is better to make it as quickly as possible, than to put it off for an indefinite period. It agrees with the data obtained by A. DiFabio, according to which procrastination is negatively associated with constancy in achieving the goals. Positive association of procrastination with neuroticism found by A. DiFabio was confirmed in our study (DiFabio, 2006).

The indices of personality anticipation competence in EMS workers are positively associated with extraversion and communicational factor $(0.523 a t p<0.05)$. That is, the more such traits as assertiveness, enjoyment of human interactions or social settings and risk-taking are expressed, the more sociable and active they are, the higher is the 
workers' ability to anticipate and foresee the patient's behavior in one situation or another.

\section{Conclusion}

The data resulting from the study suggest qualitative difference in the decision-making process between the emergency doctors and the outpatient physicians as far as informational, procedural/cognitive, emotional - volitional, motivation and communicational factors are concerned. On decision making, the emergency physicians as compared with control subjects demonstrate their readiness for decisions at any time, skills for timely signal detections and carrying out required actions without putting the work off for a later time; and doubt in choice between alternatives is not characteristic of them. Extraversion indices have no significant differences in medical workers of the experimental and control groups. The workers of the control group are calmer, less anxious and less susceptible to stress.

The work with information in EMS medical workers differs considerably from that of the outpatient physicians. Sometimes emergency physicians have shortage of information, limited quantity of information confining the rationality of decision resulting in increase of clinical intuition role relying on the doctor's experience. Moreover, high rate of obtaining, inconsistency of information, redundancy and arrhythmy in presentation of information, subjective ambiguity of the information presentation time provide skills for paying attention to atypical manifestations, acting without applying a template, but developing a creative approach to problem solving. The EMS medical workers control their emotional state better than the inpatient workers on decision making

Hence, particular attention should be paid to teaching the effective decision making skills in extreme uncertainty situation when teaching doctors. To improve effectiveness of the medical service activities, the obtained data of the carried out study can be used by the emergency medical services coordinators for professional selection of emergency doctors, be a source of information as basic data for further studies in this field; and applied by the psychologist working in emergency call services.

\section{References}

Colman, A.M. (2009). A dictionary of psychology. (3rd ed.). Oxford: university press.

Di Fabio, A. (2006). Decisional procrastination correlates: Personality traits, self-esteem or perception of cognitive failure? International Journal for Educational and Vocational Guidance, 6, 109-122.

Grupman, J. (2008). Kak dumayut doktora [How doctors think?]. Moskva: Izdatel'stvo Eksmo.

Kaneman, D. (2014). Dumay medlenno, reshay bystro [Thinking, fast and slow]. Moskva: Izdatel'stvo AST.

Karpov, A.V. (2003.) Psikhologyia prinatiya resheniya v professional'noi deyatel'nosti [Psychology of decision making of professional activity]. Moskva: Izdatel'stvo IP RAN.

Kornilova, T.V. (2013). Mel'burnskiy oprosnik prinatiya resheniya: russkaya adaptaciya [Melbourne decision making questionnaire: a Russian adaptation]. Journal of Psychological study, 6, 31.

Leontev, D.A. (2014). Psikhologiya vybora [Psychology of choice]. Psychological Journal, 35, 6, 56-68.

Luce, M. F., Payne, J.W., Bettman J.R. (2005). Emocional'naya priroda kompromissnikh resheniy [Affective natura of compromise decisions]. In: Wharton on making decisions. S. J. Hoch \& H.C. Kunreuther (Eds.). Moskva: Izdatel'stvo "IK"Analitika", 19-40.

Mendelevich, V.D. (2011). Anticipacionnye mechanism nevrozogeneza [Anticipation mechanism of neurosis genesis]. Kazan: Izdatel'stvo Medicina.

Ryabova, T.V., Shevtcov, M.N. (2010). Metodika diagnostiki osobennostey sistemnogo prinatiya resheniya [The diagnostic method of system decision making peculiarities]. Journal of Psychological study, 4, 12.

Standing, M. (2011). Clinical Judgement and decision Making for Nursing Student. Learning Matters Ltd.

Steel, P. (2007.) The nature of procrastination: A meta-analytic and theoretical review of quintessential self-regulatory failure. Psychological Bulletin, 133(1), 65-9. 
ISSN 2039-2117 (online)

ISSN 2039-9340 (print)
Mediterranean Journal of Social Sciences MCSER Publishing, Rome-Italy
Vol 6 No $6 \mathrm{~S} 5$

December 2015 